\title{
( Impact of Digital Marketing as a Tool of aße Marketing Communication: A Behavioral Research House Perspective on Consumers of Bangladesh
}

\begin{abstract}
Ahmad Bin Yamin
Lecturer, Faculty of Business Administration, Fareast International University, Banani, Dhaka-1213, BANGLADESH

"E-mail for correspondence: yamin.fba@ fiu.edu.bd

Received: July 08, 2017;

Accepted: Oct 25, 2017;

Published: Dec 16, 2017

Source of Support: Nil

No Conflict of Interest: Declared

ABSTRACT

This study shows the impact of digital marketing on behavioral prospect of consumers of Bangladesh. For conducting this study a sample of Bangladeshi consumers are surveyed to attain their behavioral pattern on digital marketing. Modern day marketing has been going through a radical change. Fast moving marketing trends based on the growth and innovation of new technologies as well as portable communication devices influencing the customer behavior significantly. A well designed marketing plan with specific digital marketing tools is the demand in the integrated marketing communication plan for this tech friendly environment. High speed internet connectivity brings massive number of young crowd in social media indicating marketer should be more focused and concentrated in digital marketing tools for effective and efficient targeting of market as well as to achieve other organizational goals.
\end{abstract}

Keywords: Digital Marketing, Marketing Communication, Consumer, Bangladesh

\section{INTRODUCTION}

Digital marketing is a broad marketing concept that describes the marketing of products or services using digital technologies, mainly on the Internet, but also includes display advertising, mobile phones, and any other digital medium. Digital marketing is the promotion of products or brands through one or more forms of electronic media and it differs from conventional marketing in that it involving the use of channels and methods that allow a business to analyze marketing campaigns and understand what is working and what isn't in a quicker and more authentic way.

Typically digital marketers examine things like what is being viewed, how often and for how long, sales conversions, what content works and doesn't work, etc. Internet is the most widely use channel in digital marketing, yet there are other means including wireless text messaging, electronic billboards, mobile instant messaging, mobile apps, podcasts, digital television and radio channels, etc. The overall digital marketing concept actually covers all the digital platforms and modern technologies in interaction, use, execution and control of marketing strategies and plans for better customer satisfaction and to reach organizational goal.

\section{STATEMENT OF THE PROBLEM}

Digital media is so all-encompassing that consumers have access to information any time and any place they want it. In ancient period only specific information were available regarding on business. Digital media is fast and widely growing source of information, entertainment, news, shopping and social interaction. Consumers have access to wide range of information where they are not only informed to what their companies say about their brands, but also what the medias, friends, relatives, peers, etc., are saying. Over the ages it have been proved that consumers trust them more than companies. Consumers want brands which they can trust, companies which are familiar with, interaction that are personalized and relevant, and offer customized to their needs and preferences in a convenient way. Most of the consumers use several digital channels and a variety of devices that use different protocols, specifications and interfaces - and they interact with those devices in different ways and for different purposes. Digital Medias are relatively cheap, compared with traditional media, affordable for most new and small size business as well. Consumers leave behind a huge trail of data in digital channels. It is very difficult to handle and operate such huge bank of data and execute them in operation. This study will try to analyze the impact of digital marketing and consumer's behavioral response towards it. 


\section{ObJective OF The Study}

- To identify the factors that influence consumer's psychology.

- To identify the digital media's impact on demography.

- To measure the relative impact of each promotional tools on consumer.

- Learning social media in Bangladesh and its impact on marketing and brand communication.

- Significance of social media compared to other medium of brand communication and its benefits.

\section{LITERATURE REVIEW}

Though the term digital marketing is comparatively new yet its impact is huge, intimidating and complicated. Being one of the important tools in promotion mix, businesses are looking for a definite way to start and accommodate digital marketing but they have lack of understanding and implementing it. Now-a-day, social Medias such as Facebook, Google Plus, Twitter, and other social Medias have effectively transformed the attitudes and perceptions of targeted consumers. This Digital marketing was done through assessable wide network of customers with reliable data with real-time feedback of customer experiences. Generally digital marketing is the use of modern technologies to help marketing activities to improve customer knowledge by matching their needs and wants (Chaffey, 2013). Since the start of Yahoo in internet industry in 1994, many companies started to maximize their presence in online with care (Smyth 2007). 2001, market was dominated by Google and Yahoo for search optimization. 2006, internet search traffic grew hugely; the rise of search engine optimization grew for major companies like Google (Smyth 2007). Being the growth and use of smart phones and internet connectivity in 2010s, in the developed world, companies have understood the importance of digital marketing. It has been observed that to do business well or successful managing of customer both online and traditional methods are needed simultaneously (Parsons, Zeisser, Waitman 1996).

Online advertising is a powerful marketing tool for building brands and increasing traffic for firms to achieve success (Song, 2001). Marketer's expectations when evaluating the results and measuring accomplishment for advertisement budgeting, digital marketing found more cost-efficient for measuring ROI on advertisement (Pepelnjak, 2008). In term of result achievement, it has been proved in Singapore that digital marketing tools are more effective and useful for achieving results (Teo, 2005). The growth in digital marketing has been due to the rapid advance in technologies and changing market dynamics significantly (Mort, Sullivan, Drennan, Judy, 2002). Digital marketing in term to deliver result for businesses, digital content such as navigation, accessibility, customization and speed are defined as the key features for marketing (Koiso-Kanttila, 2004). Another vital role of using digital medias to achieve success is that the use of word-of-mouth WOM on social media and for making the site popular among mass population (Trusov et al., 2009). Moreover, word-of-mouth is linked with creating new members and increasing traffic on the website, pages or online events which in return increases the visibility in terms of marketing communication. Facebook, the most popular tool for social communications, has opened the door for marketers to communicate with millions of people about products and services and has opened new marketing opportunities. Ensuring this to be successful it is required for the business to setup effective communication strategies to engage the customers and enhancing their experience on specific product or service (Mangold and Faulds, 2009). In the recent time market shape and diversity all over the world has been changing pretty fast more young audience accessing internet and social media, actually strategic integration approaches are considered in organization's marketing communication plan (Rohm \& Hanna, 2011). Researchers have find out that online services tools are more influencing than traditional mode of communication (Helm, Möller, Mauroner, Conrad, 2013). Marketing professionals have positive outlook and findings that users' experience increase in self-esteem and enjoyment along with the use and involvement with social media (Pai and Arnott, 2013). Research also showing a positive sign that online experiences affect the mental process of consumers and improve their buying decision online (Cetină, Cristiana, Rădulescu, 2012).

The Internet is the most powerful tool for businesses (Yannopoulos, 2011) and it becomes vital for marketers for marketing through digital marketing platforms. That's why marketers should focus and plan strategies uniquely for ever-changing online presence. Branding, pricing, distribution and promotional strategies are needed to be separately understood in digital marketing.

\section{Methodology}

The study will be carried out with both primary and secondary data. In order to pursue consumers' response to marketer's activity, these aforementioned factors will also be examined to look for whether they contribute in a positive manner. Quantitative data will be collected from direct consumers through a survey to understand their perception. The primary data will be collected through structured and unstructured questionnaire from samples of consumers from Bangladesh. Samples of 120 participants are conveyed questionnaire for the collection of primary data.

This research will conduct a qualitative research in order to identify the problem properly by using secondary data from different sources i.e. information from various publications, journals, websites, etc. After, getting an indepth view of the problem, a descriptive research was conducted to find out factors that affect consumers' perception regarding marketing activities of different companies to attract consumers. In this regard, impact of different digital marketing tools like social media -video, image, audio or text contents as well as other digital 
medias are understand, evaluate and perceived for understanding attractions of consumers' concern.

\section{MARKETING THROUGH DIGITAL MEDIA AND ITS IMPACT}

The relationship between a brand and consumer has changed dramatically due to the impact of social media. It has given immense control and power to consumers and large corporations and well-known brands no longer have the so called upper hand.

\section{Definition of Digital Marketing}

Digital marketing is an umbrella term for the marketing of products or services using digital technologies, mainly on the Internet, but also including mobile phones, display advertising, and any other digital medium.

Digital marketing has developed strongly since the 1990s and 2000s and it has changed the way brands and businesses utilize technology and digital communication tools for their marketing. Digital marketing campaigns are becoming more widespread as well as efficient, as digital platforms are increasingly incorporated into marketing plans and consumers' everyday life, and as people use digital devices instead of going to physical shops.

Digital marketing is in fact a modern marketing communication tool to use different electronic devices and technologies to carry marketing messages to consumers more effectively and efficiently. Businesses leverage digital channels such as Google search, social media, email, and their websites to connect with their current and prospective customers.

Digital marketing vehicles such as search engine optimization (SEO), influencer marketing, search engine marketing (SEM), content marketing, content automation, data-driven marketing, campaign marketing and ecommerce marketing, social media marketing, social media optimization, e-mail direct marketing, display advertising, e-books, and optical disks and games are becoming more common in our advancing technology. Digital marketing now-a-days extends to non-Internet platforms that provide digital media, such as mobile phones (SMS and MMS), on-hold mobile ring tones and callback.

\section{Meaning of Digital media}

While defining digital media, it is meant normally that any media that are encoded in a machine-readable format are called as digital media. Generally digital media can be created, viewed, used, distributed, modified, reviewed and preserved on digital electronics devices. The following can be classified as the examples of digital media: computer programs and software; digital imagery, data and databases, digital video; video games; web pages and websites, including social media; digital audio, such as mp3s; and e-books etc. Digital media are often contrasted with print media, such as printed books, newspapers and magazines and other traditional (analog) media, such as pictures, film or audio tape though these flat form are uniquely identifiable and separable.

\section{Social Media as Marketing Tools}

Field evidence and an increasing number of studies provide already a good picture on the basic patterns of engaging Social Media as part of the marketing strategy (Bernhoff and Li, 2008; Prahalad and Krishnan, 2008; Deighton and Konrfeld, 2009).

As marketing tool social media is p[laying both active and passive role. The Passive approach is based on utilizing the Social Media public domain as potential source of customer voice (Anderson, 2007). The Active approach is utilizing the Social Media as tools of communication, direct sales, customer acquisition and customer retention (Bryan et al., 2007).

The marketing objective is to provide marketers with information about market needs, customer experiences, competitive movements and trends. By using social media marketers can know about consumer perception about the product as well as the competitors move on similar products to make and apply the strategic marketing plan.

\section{Growth and Impact of Digital Marketing in Bangladesh}

Bangladesh, as an emerging economy, has embraced technology at a rapid speed. The diffusion of the telecom sector, mobile financial transactions and advent of internet based applications designed by businesses and supported by the tech friendly government, assistances actually creates and widening the opportunities for different sector people.

With the explosion of smart gadgets (phones and tabs), growth of $3 \mathrm{G}$ internet connectivity resulting into mass level Social Networking as well as the integration of Mobile Financial Services (MFS) changing the business and socio economic environment of Bangladesh. The proliferation of E-commerce industry with the help of mass people's integration in digital world triggers the digital marketing in Bangladesh.

This development trend has intensely impacted over the last few years, the way people live their daily lives, correspond with each other as well as their consumption pattern and behavioral changes help to gain success particularly in industries like Food and Beverage, other FMCG, Consumer Durable products, Telco, Apparel, Footwear as well as Tourism and Healthcare products.

With the Bangladesh Bank, central bank of Bangladesh, step to permit the implementation of e-payment gateways in 2009, e-commerce businesses have grown rapidly. It is observed that many B2C businesses operates under the hybrid model incorporating "cash on delivery" mechanisms actually shows that the system is not widely accessible or useable by mass consumers. Within five years between 2007 and 2012 the e-commerce and online auction area grew by $10.4 \%$ and is anticipated to grow by $8.8 \%$ 
annually during 2017. The total numbers of businesses operating in the e-commerce sector are projected to grow exponentially to $61 \mathrm{~K}+$ over the next five years as reported by IBIS World.

These digital improvements happened around us, taking part within last three or four years made our lifestyle easier. Digital Marketing improvement gives the brands an opportunity to reach the maximum number of audience with more cost effective way. That's why the brands also prefer this communication platform to introduce, innovate and implement their marketing strategies through this digital media.

\section{DISCUSSION ON ANALYSIS OF DATA}

On the basis of collected data from participants, the following analysis has been made where the discussion on frequency of usage of social media, preference of social media, preferred internet platform, internet using expenditure, popularly followed brand and tools etc. are conducted to find a suitable guideline for marketers who are promoting their products already on digital platform and for also for them who want to do the same.

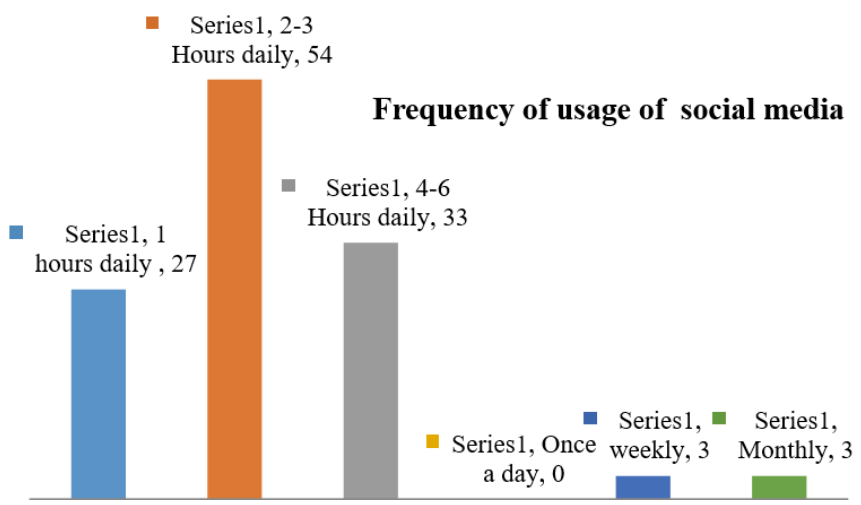

This research was done on young generation and it is revealed that the frequency of using internet per day is 2 to 3 hours (54), which is nearly $45 \%$ of the total population. The personal interview with respondent disclosed that most of them use frequently but not continuously for 30 or more minutes. That indicates that they are mostly updating friends' feed or current info. However, it is very significant part of time that they are consuming ( 1 to 6 hours) of majority of the population exposes as the potential target for digital marketer.

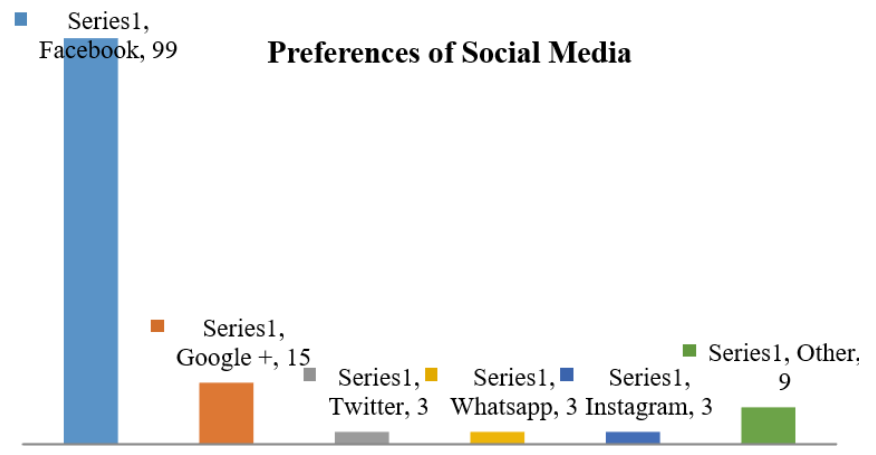

Majority of the respondents showed their preferred social media platform is Facebook (99) way ahead of the second largest preferred Google Plus (15) which is comparatively new. The lack of instagram or twitter presence showing that young generation among this group are not aware or not interested on those platform.

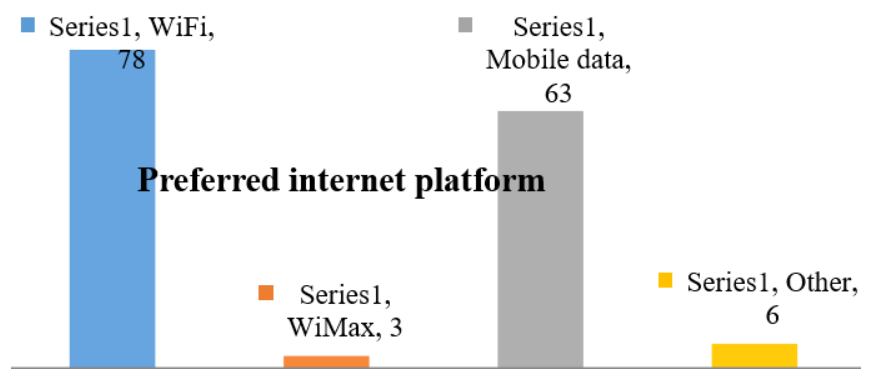

The preferred platform to use internet is varying among different types. Most respondents' using WiFi (78) or Mobile data (63) indicating these two are the most common platform. A good number of people are actually using mobile data to use internet confirming mobile interface as one of the vital tools to interact with customer and potential customer for digital marketing.

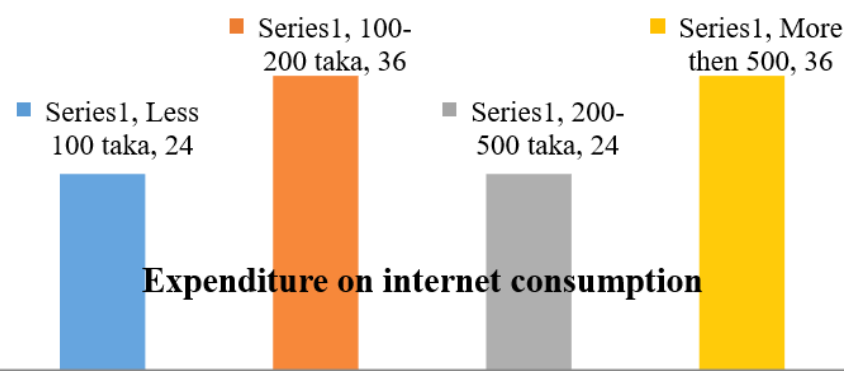

Among the respondent group it is also important that how much they spend on internet consumption, which may represent their interest in downloading, using and viewing contents. Marketer should know that majority are young and have less income or ability to spend on internet consumption. A group showing 100-200 taka per month that is 36 respondents but also another group showing they spend 500 and more taka means the expenditure on it is growing fast.

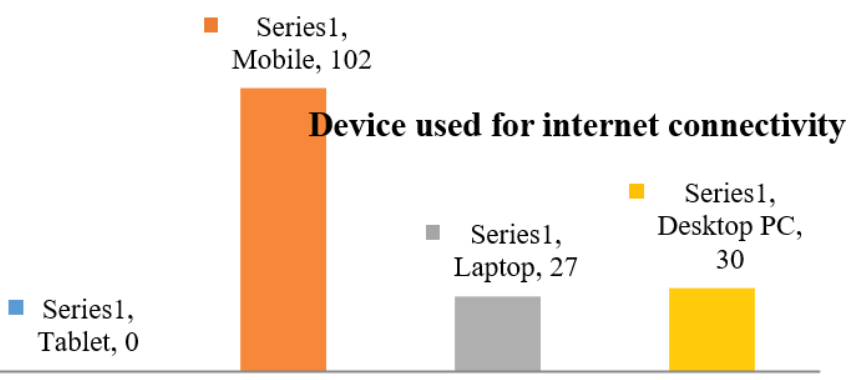

The scenario of device preferred by the most users are changed radically. Previously desktop or laptop was widely used but now about $80 \%$ plus that is 102 respondents preferring the mobile device as a way to reach internet. Mobile device being portable and smaller screen 
indicates marketer to create and promote compatible contents.

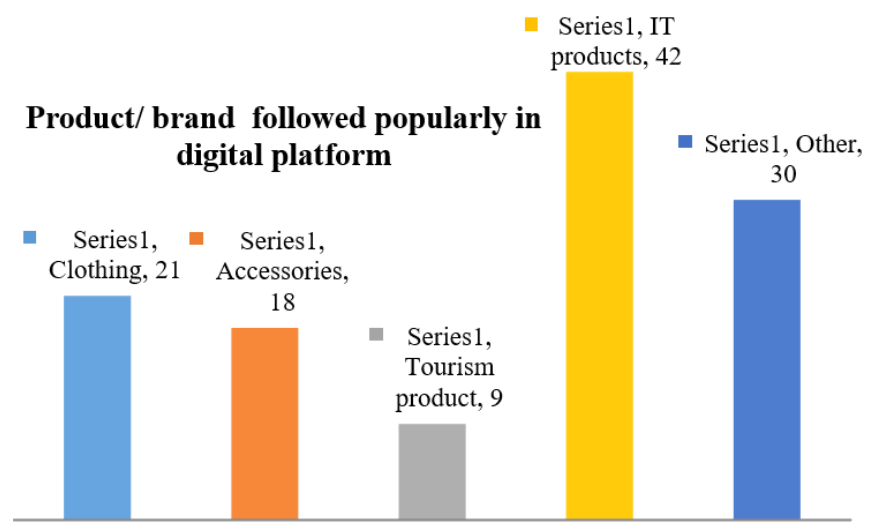

Most interestingly majority of respondents showing interest in IT products when searching or shopping online, though clothing and accessories are also searched or shopped, but significantly less only 9 choose tourism products though tourism industry promoting hugely in Facebook or online media. But it is also certain the group responded are young and not enough expenditure to afford tourism product but more aware and interested in new technologies and gadgets.
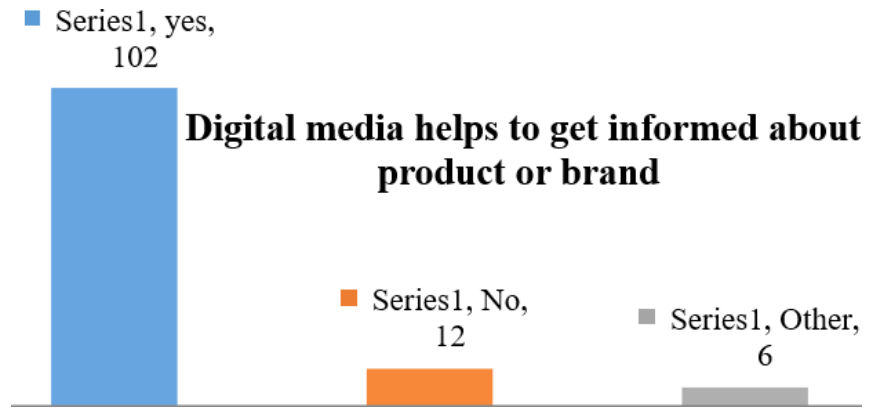

The good sign about promoting through digital media or internet marketing is, most respondent agrees on its reaching to get information about the product or brand is helpful. So, it is widely used in searching, getting information or alternative evaluation by the respondents.

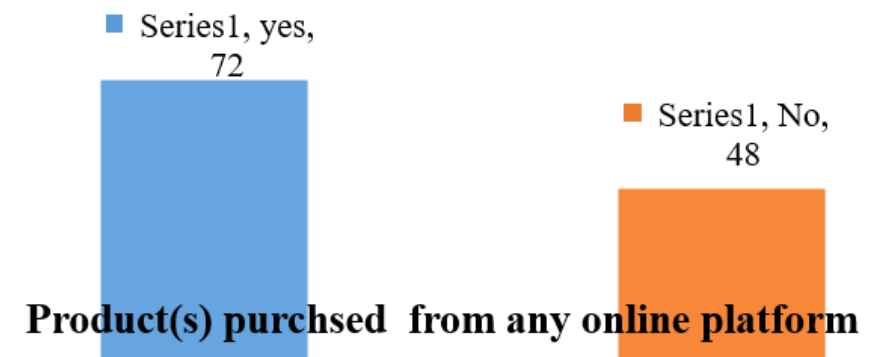

Though the number of user and information search through internet is almost $90 \%+$ of respondents yet many of them (48) are not willing to buy from it. It indicates the buyers are not comfortable either because of the lack of trust or delivery charge. Online money or use of electronic fun transfer might be the other reasons. But it is important though they don't buy through online platform still digital media plays great role in gathering information on products.

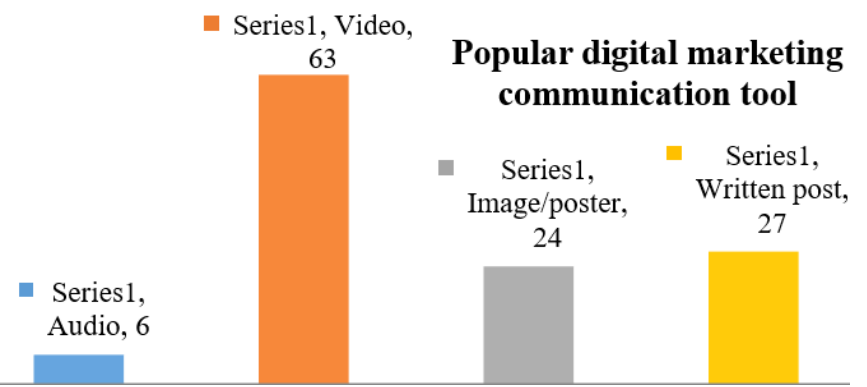

This research was also done to find out the popular tool in digital or online marketing communication. Majority of the respondents (63) actually following video contents and interestingly majority video contents in Facebook are either motivational or ethical contents. So marketer should be aware on which contents mass population are viewing and the reasons behind it. Audio is the least preferred tool but about $20 \%$ focus in image and $25 \%$ reading text post in online Medias.

\section{RECOMMENDATIONS}

An integrated marketing communications plan must include a qualitative and quantitative market research section which provides a guide to plan strategy for better marketing of products and services by understanding consumer behavior. By this research it can be said that as a modern tool of marketing communication social media playing very significant role in the marketing platform to reach consumer closely. There are some suggestions in light of the survey conducted:

- As the research found that people using social media daily for 2 to 3 hours so marketer can easily try to grab their attention about the product.

- Most of the participants said they use Facebook as social media most so marketers should pay more attention to use this platform more effectively. From the survey it is also seen that young generation are not interested or not aware about other media so concerned authority may try to grab attention of the potential users.

- $\quad$ Research is showing people spend 500 and more taka to use internet for social media that means the expenditure on it is growing fast and they giving a good amount of time in using internet. It is high time for marketers to attain their goal to attract the customer.

- Marketers may investigate how often their competitors are posting and conduct industry research to see the ideal amount of content to publish per day on each channel and work accordingly.

- Each social channel needs to be treated as a separate entity by digital promoters. There can be content that is spread across all channels to grab mass customers. 
- People are using internet more from mobile than PC so it is became easy to go close to customers and connect frequently.

- There is good news for IT promoters that young generations are more interested in following IT products and brands. Some more attention in promoting this type of product can create a good marketing platform.

- Research shows people use digital media to get informed about product or brand so marketers should be more active in this platform.

\section{ConcLusion}

This research founds that the digital marketing contribution in aggregate marketing initiatives among the mass customers, especially on their behavioral and inflecting patters. Digital marketing tools and concepts are taking over traditional methods world widely yet it is comparatively new among mass consumer market in Bangladesh. Marketing professionals are dubious about the usage and benefits of digital marketing and have been observed in lack of proper segmenting, proper market targeting as well as improper and confusing positioning of product. It is for sure that the growth of internet and mobile communication widening the horizon for more people to reach and communicated, hence the proper market research and followed by a comprehensive inclusions of digital marketing tools and strategies in a firms integrated marketing communication can surely ensures bring more effective and efficient marketing.

\section{REFERENCES}

A Munshi, MSS MUNSHI, 2012, Digital matketing: A new buzz word, International Journal of Business Economics $\mathcal{E}$ Management Research, Vol.2 Issue 7, July.

A Sundararajan, Leonard N., 2003, Pricing Digital Marketing: Information, Risk Sharing and Performance, Stern School of Business Working NYU

Anderson, P. (2007): What is Web 2.0? Ideas, technologies and implications for education, in: JISC Technology and Standards Watch, Feb, 1-64.

Bernoff J. and Li C., (2008), Harnessing the Power of the Oh-So-Social Web, MIT Sloan Management Review, vol 49, nr 3, pp 36-42

Boyd, D. M. \& Ellison, N. B. 2007. Social Network Sites: Definition, History and Scholarship, Journal of Computer Mediated Communication vol 13, issue 1, 210-230.

Bryan L., Matson E., Weiss L., (2007), Harnessing the power of informal employee networks, The McKinsey Quarterly 2007, nr 4

Cetină. J, Cristiana. M, Rădulescu. V, 2012, Psychological and Social Factors that Influence Online Consumer Behavior, Procedia - Social and Behavioral Sciences, Vol 62, Page 184- 188.

Chaffey. D, (2013) "Definitions of Emarketing vs Internet vs Digital marketing", Smart Insight Blog, February 16, 2013.

DC Edelman, 2010, Four ways to get more value from digital marketing, McKinsey Quarterly

Deighton J. and Kornfeld L., (2007), Digital Interactivity: Unanticipated consequences for markets, marketing, and consumers, Harvard Business School working paper, http:/ /hbswk.hbs.edu/item/5783.html

G. Reza Kiani, (1998) Marketing opportunities in the digital world, Internet Research, Vol. 8 Iss: 2, pp.185 - 194.

Guoying Zhang, Alan J. Dubinsky, Yong Tan, 2013, Impact of Blogs on Sales Revenue, International Journal of Virtual Communities and Social Networking, Vol .3, August, Pg 60-74

Helm R, Möller M, Mauroner O, Conrad D, 2013, The effects of a lack of social recognition on online communication behavior, Computers in Human Behavior Vol 29, pg 1065-1077.

Koiso-Kanttila, N. (2004), "Digital Content Marketing: A Literature Synthesis", Journal of Marketing Management, Volume 20, Issue 1-2, pg-45-65, 2004.

Mangold G. and Faulds D., "Social media: The new hybrid element of the promotion mix", Business Horizons, Volume 52, Issue 4, , Pages 357-365, July-August 2009

Mort, Gillian Sullivan; Drennan, Judy, (2002), "Mobile digital technology: Emerging issue for marketing", The Journal of Database Marketing", Volume 10, Number 1, 1 September 2002, pp. 9-23.

Pai. P, Arnott. DC, 2013, User adoption of social networking sites: Eliciting uses and gratifications through a means-end approach, Computers in Human Behavior, Volume 29, Issue 3, Pages 1039-1053, May.

Parsons. AJ, Zeisser. M, Waitman. R, 1996, Organizing for digital marketing, McKinsey Quarterly.

Pepelnjak. JC, 2008, Measuring ROI beyond the last ad, Atlas Institute, Digital Marketing Insight

Prahalad C.K. and Krishnan M.S. (2008), "The new age of innovation: Driving co-created value through Global Networks" McGraw-Hill (2008)

Rohm and Hanna C, 2011, We're all connected: The power of the social media ecosystem, Business Horizons, Volume 54, Issue 3, May-June, Pages 265-273.

Smyt. G, (2007), “The History of Digital Marketing”, Inetasia, 2007.

Song YB, 2001, Proof That Online Advertising Works, Atlas Institute, Seattle, WA, Digital Marketing Insight

Teo, T. S.H. (2005), “Usage and effectiveness of online marketing tools among Businessto-Consumer (B2C) firms in Singapore", International Journal of Information Management, Volume 25, Issue 3, June Pages 203-213, 2005.

Trusov M., Randolph E. Bucklin, Koen Pauwels (2009). Effects of Word-of-Mouth versus Traditional Marketing: Findings from an Internet Social Networking Site. Journal of Marketing: Vol. 73, No.5, pp.90-102.

Yannopoulos. P, 2011, Impact of the Internet on Marketing Strategy Formulation, International Journal of Business and Social Science, Vol. 2 No. 18; October.

YS Wang, TI Tang, JE Tang, 2001 An instrument for measuring customer satisfaction toward web sites that market digital products and services, Journal of Electronic Commerce Research, VOL. 2, NO. 3,

$--0--$

SOCIAL SCIENCE RESEARCH NETWORK 2171 Monroe Avenue, Suite 203, Rochester, NY 14618, USA http://www.ssrn.com/en/

AJTP Link: http://www.ssrn.com/link/American-Journal-Trade-Policy.html 